\title{
Assessment of differences between products obtained in conventional and vacuum spray dryer
}

\author{
Fernanda de Melo RAMOS ${ }^{1 *}$, Cíntia Carla Melgaço de OLIVEIRA ${ }^{1}$ Ana Silvia Prata SOARES ${ }^{1}$, \\ Vivaldo SILVEIRA JUNIOR ${ }^{1}$
}

\begin{abstract}
In this work, an experimental unit of a vacuum spray dryer was built. This prototype attempted to combine the advantages of freeze-drying (drying at low temperatures due to vacuum) and spray drying (increase of surface area aiming the improvement of heat transfer efficiency). Maltodextrin solutions were dried in the vacuum operated equipment and in conventional spray dryer. The vacuum spray dryer system allowed obtaining powder at low temperatures due to the lowering of pressure conditions $(2-5 \mathrm{kPa})$ inside the drying chamber. The products obtained in the two systems were characterized and compared for particle size distribution, moisture content, water activity, bulk density and solubility in water. The processes yields were also evaluated and compared. The vacuum spray dryer system allowed the production of larger, more soluble and less dense particles than those obtained in the conventional configuration of the equipment, resulting in drier and, therefore, with lower water activity particles. Thus, the use of the vacuum spray dryer as a drying technique may be an alternative for the production of powder rich in thermosensitive compounds.
\end{abstract}

Keywords: thermosensitive compounds; vacuum spray dryer; vacuum; maltodextrin.

Practical Application: Drying of powder rich in thermosensitive compounds in dryers type spray dryers.

\section{Introduction}

The food industry often uses the unit operations of heat transfer (insertion or removal) in order to reduce the water content or make it unavailable for degradation processes such as Maillard reactions, oxidation or microbial growth (Levine \& Slade, 1995). Thus, the processed food can be preserved for longer times. Among the unit operations, the drying process has the advantage of reducing the volume to be transported and permit the incorporation of more accurate formulations. One method of drying is the atomization process, conducted in an equipment called spray dryer. In these dryers, the food powder is obtained by the atomization of the feed material in a drying chamber when in contact with hot air in temperatures ranging from 150 to $250{ }^{\circ} \mathrm{C}$ (Islam et al., 2016).

Vitamins, enzymes and probiotics are thermolabile compounds that may be degraded during thermal processing (Islam et al., 2016; Kitamura et al., 2009). Studies have shown the degradation of thermosensitive compounds in spray drying of orange juice (Zare et al., 2012), acai berry juice (Tonon et al., 2009) and cells of Lactococcus lactis (Fu \& Etzel, 1995). An alternative to drying functional foods in spray dryers is the reduction of the pressure inside the drying chamber, what would lead to a decrease in water evaporation temperature. This practice is already used in lyophilization process, which classifies it as the more suitable process for processing sensitive products. However, lyophilization might become very expensive since it requires a prior freezing of the food matrix and for been an extremely slow process (minimum of twelve hours) due to long diffusion of water molecules. Thus, the hypothesis of this work is that the formation of droplets by atomization under vacuum can significantly reduce drying time, combining the advantages of both drying methods.

On vacuum spray dryer (VSD), the drying temperature can be maintained at $40-60^{\circ} \mathrm{C}$, which will substantially reduce the loss of heat sensitive functional ingredients (Islam et al., 2016). Few studies in the literature were found with similar cases. Aoyama et al. (2009) analysed experimentally drying characteristics of the VSD and stated that the process produces powders at lower temperature $\left(40-60^{\circ} \mathrm{C}\right)$ due to the lowering of the pressure conditions inside the drying chamber (10-20 kPa). Kitamura et al. (2009) developed and conducted the drying of probiotic foods in a VSD at lower temperatures (about $40^{\circ} \mathrm{C}$ ) when compared to drying in conventional spray dryer. Semyonov et al. (2011) used an ultrasonic vacuum spray dryer to produce highly viable probiotic cells. Islam et al. (2016) dried concentrated orange juice in VSD and evaluated the effects of vacuum spray drying on the physicochemical properties of powdered orange juice. In works by Aoyama et al. (2009) and Kitamura et al. (2009) hot water circulated in the drying chamber jackets. According to the authors, the hot water circulation has the purpose of preventing the evaporated moisture to condense on the inner wall surface of the drying chamber. Islam et al. (2016) used superheated steam as a heating medium. Unlike the cited studies, we did not use the heat source system in our work. 
Therefore, the aim of this study was to design a vacuum spray dryer and evaluate the differences between the particles obtained by the VSD and by conventional spray dryer.

\section{Material e methods}

\subsection{Material}

\section{Raw materials}

Maltodextrin (MOR-REX ${ }^{\bullet}$ 10DE, Ingredion, Brazil) was used for the formulation of the polymer model solution which was submitted do drying processes. Its basic composition is sugar in the form of powder, completely soluble in water and produced by corn starch hydrolysis.

\section{Vacuum spray dryer (VSD)}

Figure 1 illustrates the schematic diagram of the process and instrumentation of the VSD. The description of the instrumentation and the prototype is: TK-101, feed solution storage tank; P-101, peristaltic pump; P-102, vacuum pump 01; P-103, vacuum pump 02, P-104, vacuum pump 03; C-101, air compressor; $\mathrm{V}-101$, needle valve at compressor outlet; V-102, needle valve after the flowmeter; V-103, ball valve in vacuum line - Pump 01; V-104, ball valve in vacuum line - Pump 02; V-105, ball valve in vacuum line - Pump 03; TT-101, temperature transmitter in feed solution reservoir; TT-102, temperature transmitter at the top of drying chamber; TT-103, temperature transmitter at the bottom of drying chamber; TT-104, temperature transmitter of ambient air; TT-105, temperature transmitter of atomization air; MT-101, relative humidity sensor; PT-101, pressure transmitter at the top of the drying chamber; FI, rotameter.

The system was equipped with a peristaltic pump (Marterflex ${ }^{\oplus}$,United States), double fluid atomizer (Labmaq, Brazil), stainless steel drying chamber, and an air compressor
MSV 6 (Schulz, Brazil). To promote low pressure condition within the drying chamber three high vacuum pumps with rotary vanes were used RD 4 and RD 6 (Vacuubrand, Germany) and DC8D (DVP, Italy). The system instrumentation used temperature sensors (Pt100 resistance thermometers) with an accuracy of $0.2^{\circ} \mathrm{C}$ and 0.99 linearity; pressure sensors (ICC-Press, 78703 series); relative humidity and temperature transmitter RHT-WM (Novus, Brazil); flowmeter "N" (OMEL", Brazil), logger of NOVUS data logger (Novus, Brazil) and a remote computer with Field Chart 1.76 software to perform the readings of working units.

\subsection{Methods}

\section{Model solution drying in vacuum spray dryer (VSD)}

The VSD drying was performed in an experimental prototype. The operating conditions adopted in the process were determined after preliminary characterization tests of the process. The air flow used was $1.2 \mathrm{~m}^{3} / \mathrm{h}$ and 1.2 bar pressure in the line. The maltodextrin solution in a concentration of $40^{\circ}$ Brix was transported to the atomizer through a peristaltic pump at a flow rate of $1.07 \mathrm{ml} / \mathrm{min}$. It was used three vacuum pumps associated in parallel to promote the low pressure condition inside the chamber. Pressure and temperature inside the drying chamber were monitored, as well the relative humidity and temperature of the atomizing air

\section{Model solution drying in conventional spray dryer}

Conventional spray drying was performed on a mini spray dryer LM MSD 1.0 (Labmaq ${ }^{\circ}$, Brazil) with a stainless steel drying chamber and cyclone. The atomizer was the same used in construction of the VSD, a stainless steel double fluid nebulizer atomizer assembly (pneumatic) (Labmaq ${ }^{\oplus}$, Brazil), consisted by the stent and the $1.0 \mathrm{~mm}$ atomizer nozzle cover of internal and

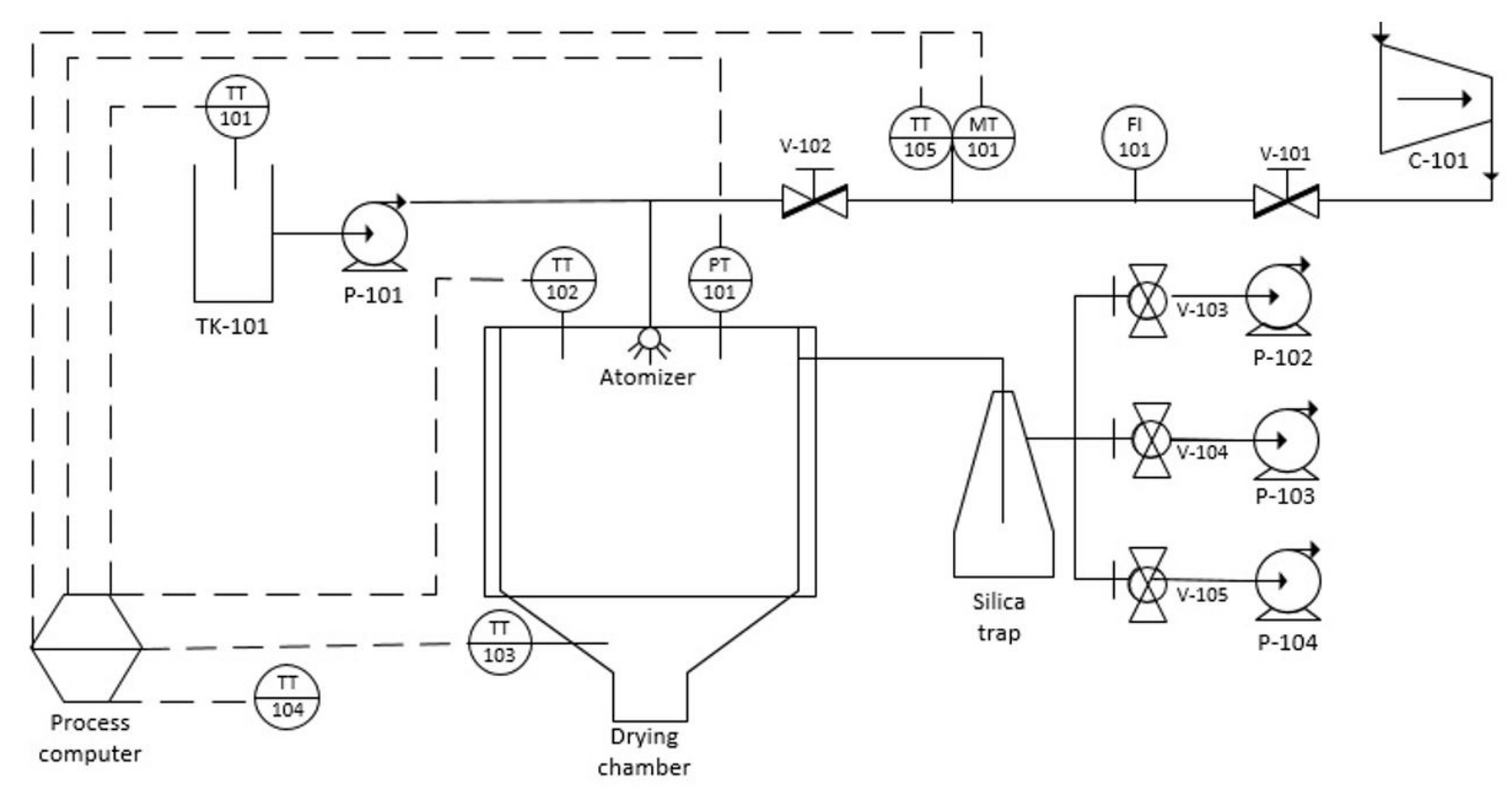

Figure 1. Diagram of process and instrumentation of the vacuum spray dryer (VSD) prototype. 
external mixing type. The compressed air flow was $2.4 \mathrm{~m}^{3} / \mathrm{h}$ and the drying air flow was $90 \mathrm{~m}^{3} / \mathrm{h}$. The $40^{\circ}$ Brix model solution was transported to the atomizer through a peristaltic pump at a flow rate of $11.67 \mathrm{~mL} / \mathrm{min}$. The drying air temperature was adjusted to $170{ }^{\circ} \mathrm{C}$ and the temperature recorded at product outlet was $112^{\circ} \mathrm{C}$.

\section{Characterization of particles obtained in conventional and in vacuum spray dryer}

After the solutions drying in conventional and vacuum spray dryer, analysis were performed for physicochemical characterization of powders. We determined the moisture content, water activity, apparent density, particles size and size distribution and solubility in water. The processes yields were also evaluated and compared. In both equipment configurations, the process was performed twice.

\section{Moisture content}

The moisture content of the particles was carried out according to the methodology described by Association of Official Analytical Chemists (2005). The gravimetric method, based on water removal by heating, was carried out in forced circulation oven at $105^{\circ} \mathrm{C} \pm 5^{\circ} \mathrm{C}$.

Water activity $\left(\mathrm{a}_{\mathrm{w}}\right)$

The water activity $\left(\mathrm{a}_{\mathrm{w}}\right)$ of the samples was determined by direct measurement in water activity equipment AQUALAB DEW POINT WATER ACTIVITY METER 4TE (Decagon Devices Inc., Pulman, USA). Analysis were performed at room temperature in three replicates. The equipment has an accuracy of \pm 0.003 aw.

\section{Apparent density}

Apparent density was determined by measuring the volume occupied by $2 \mathrm{~g}$ of powder sample in a $50 \mathrm{ml}$ graduated cylindrical glass tube at room temperature (Goula \& Adamopoulos, 2004).

Particle size and size distribution

The mean diameter and particle size distribution were determined by laser diffraction technique using a Laser Scattering Spectrometer Mastersizer S (Malvern Instruments Ltd., U.K.). Approximately $50 \mathrm{mg}$ of sample were dispersed in ethanol (99.5\% purity) and added to the equipment dispersion unit, filled with the same material under constant stirring at $1750 \mathrm{rpm}$. Fraunhofer model was used to estimate the De Broukere mean particle diameter $\left(\mathrm{D}_{[4,3]}\right.$ - Equation 1$)$ and the microparticles size distribution.

$$
D_{4,3}=\frac{\sum_{i=1}^{n} n \cdot d_{i}^{4}}{\sum_{i=1}^{n} n \cdot d_{i}^{3}}
$$

Where $d_{i}$ is the droplet diameter and $n$ is the number of drops.
Solubility in water

The solubility was determined according to the methodology proposed by Cano-Chauca et al. (2005). The method consists of adding $1 \mathrm{~g}$ of the sample to a vessel containing $100 \mathrm{ml}$ of distilled water, under magnetic stirring at high speed for 5 minutes followed by centrifugation at 3000' g, also for 5 minutes. Subsequently, an aliquot of $25 \mathrm{ml}$ of the supernatant was removed and taken to an oven at $105{ }^{\circ} \mathrm{C}$ until constant weight. The solubility is calculated by the weight difference.

Yield of drying process

The process yield was calculated as the ratio between the mass of solid of the powder obtained after drying and solid mass of the atomized solution, as shown in Equation 2.

$R S(\%)=\frac{M_{S, p o w d e r}}{M_{S, \text { sol }}} \times 100=\frac{M_{\text {powder }} \times x_{S, \text { powder }}}{M_{\text {sol }} \times x_{S, \text { sol }}} \times 100=\frac{M_{\text {powder }} \times\left(100-x_{w, p o w d e r}\right)}{M_{\text {sol }} \times\left(100-x_{w, \text { sol }}\right)} \times 10$

Where $M_{S}$ is the mass of solids $(\mathrm{g}), x_{S}$ and $x_{W}$ represent respectively the concentration of solids and water, and the index powder refer to the powdered product obtained after drying and sol the solution fed into the nozzle.

\section{Statistical analysis}

All analysis were made in three replicates, except for the determination the particle size distribution, in which we carried out six readings of each sample, and the yield of the process, which was done in two repetitions. The results were statistically evaluated by analysis of variance (ANOVA) and the difference between means was performed using Tukey test at 5\% of significance level, using Minitab ${ }^{\circledast}$ software.

\section{Results and discussion}

\subsection{Characterization of particles obtained in conventional and in vacuum spray dryer}

Moisture content, water activity and solubility in water of the particles obtained in VSD and conventional spray dryer

Results of moisture content, water activity and solubility in water obtained for the particles produced in the spray dryer and VSD are shown in Table 1. The samples produced by the two types of equipment showed significant differences between them with respect to moisture, so that the VSD resulted in wetter particles.

Particles dried in conventional spray showed moisture content of less than $1 \%$, indicating a very limited availability of water to undesirable biochemical reactions. The use of high temperature drying air in the spray dryer $\left(\mathrm{T}=170{ }^{\circ} \mathrm{C}\right)$ implied a larger temperature difference between the sprayed product and the drying air, resulting in greater heat transfer and a higher evaporation of the water, reaching lower values of moisture content. Results in the same order of magnitude were observed by Carneiro et al. (2013), which evaluated the potential of maltodextrin combination with different wall materials in microencapsulation of flaxseed oil by spray drying, and Tonon et al. (2009), in which acai (Euterpe oleraceae Mart.) juice was spray dried with inlet air at $170^{\circ} \mathrm{C}$. 
Table 1. Moisture content, water activity and solubility in water of the powders produced in conventional spray dryer and VSD.

\begin{tabular}{lccc}
\hline \multicolumn{1}{c}{ Equipment } & Moisture content $(\%)$ & Water activity $\left(\mathrm{a}_{\mathrm{w}}\right)$ & Solubility in water $(\%)$ \\
\hline Conventional Spray dryer & $0.92^{\mathrm{b}} \pm 0.07$ & $0.077^{\mathrm{b}} \pm 0.006$ & $98.99^{\mathrm{b}} \pm 0.01$ \\
Vacuum spray dryer & $9.72^{\mathrm{a}} \pm 0.49$ & $0.230^{\mathrm{a}} \pm 0.010$ & $99.09^{\mathrm{a}} \pm 0.03$ \\
\hline D & & & \\
\hline
\end{tabular}

Different letters indicate statistically significant differences between the samples produced in the different types of equipment ( $\mathrm{p} \leq 0.05$ ).

In VSD system, the absence of a direct heat source compromised the final moisture content of the dried product, since there was not enough heat to promote evaporation of all water from the product, resulting in higher moisture content values. In this work, the mass transfer was due to the pressure differential. Islam et al. (2016) dried concentrated orange juice in VSD and obtained powders with moisture content between 2.29 and 3.35\%. Probably, the lower values of moisture content than those obtained in this work were the result of the superheated steam used as latent heat of vaporization source in the drying chamber.

Also, the samples produced by the different types of equipment showed a significant difference between them in relation to water activity. The samples dried by spray drying showed water activity values below 0.1 while samples produced in VSD showed values below 0.3 . Therefore, both processes have resulted in powdered products with very propitious water activity values to microbiological and biochemical stability.

The particles produced in VSD proved to be quite soluble in water and showed significant difference compared with the particles obtained in conventional spray dryer. This result was expected, since the product of VSD showed more porous appearance (Figure 2). The process performed in the conventional spray dryer configuration also resulted in soluble particles. According to Kenyon \& Anderson (1988), maltodextrin with a low $\mathrm{DE}$, such as the used in the experiments, have high solubility in cold water.

\section{Apparent density and particle size and size distribution}

The samples produced in VSD were those with the lowest apparent density. The difference in the densities of powders produced by conventional spray dryer and VSD might be related to particle size (Table 2). Smaller particles result in higher apparent density, since the agitation performed during the analysis tends to minimize the spaces between the particles, forcing the powder to occupy smaller volumes (Al-Kahtani \& Hassan, 1990). Furthermore, according to Goula et al. (2004), the greater apparent density is associated with a lower moisture content, once wetter particles may result in not fully dried agglomerates, and larger than the particles, resulting in a lower apparent density. Samples produced in conventional spray dryer had an apparent density greater than $0.8 \mathrm{~g} / \mathrm{cm}^{3}$.

The samples produced by different drying devices differ significantly from each other relative to the mean diameter. When compared, the particles had very varying diameters, so that the VSD resulted in considerably larger particles with a mean diameter greater $555 \mu \mathrm{m}$ while those obtained in spray dryer showed a mean diameter below $24 \mu \mathrm{m}$. The mean particle diameter was expressed as $\mathrm{D}[4,3]$ (De Brouckere mean diameter), which indicates the central point around which the volume of

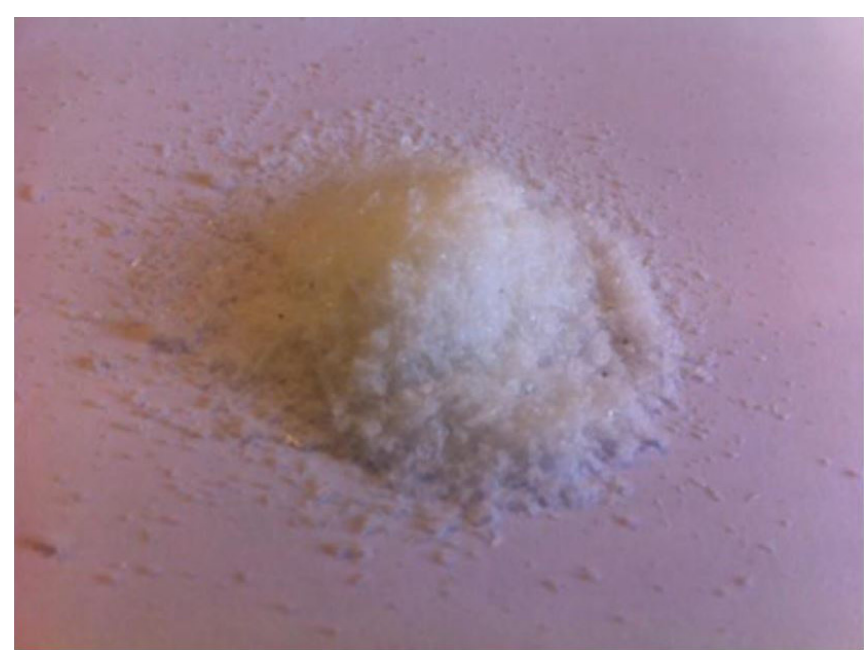

Figure 2. Powders obtained by VSD.

distribution of frequency. In Table 2, the D [4,3] values are shown for the powders produced in the two types of dryers.

Reineccius (2001) stated that when the inlet air temperature is low, the particle remains curled up and maintains a smaller diameter, while the use of higher temperatures results in larger particles due to its expansion.

In this study, the use of drying air in high temperatures resulted in smaller particle than the particles obtained in VSD. This might happened due to the high temperature in the spray dryer that caused a higher water evaporation of the product, resulting in drier and smaller particles. In the VSD, the solution to be atomized within the chamber at low pressure suffered an expansion process, which led the formation of larger particles. Moreover, the presence of more water in this product also contributes to the increase in diameter of the particles, since wetter particles tend to agglomerate. The equipment used for determining particle size has a unit of dry automatic dispersion, which possibly inhibited the measure of individual particles resulting in the significant difference presented in Table 2. Islam et al. (2016) obtained concentrated orange juice powders with smaller diameters, ranging from 6.02 to $12.84 \mu \mathrm{m}$ in a VSD. Possibly, the use of superheated steam assisted the water evaporation, and associated with the lowering of pressure conditions, allowed the obtainment of smaller and drier particles.

Factors such as the solution viscosity, the type of atomizer and the feed solution concentration also influenced the size of particles obtained from atomization drying process. According to Masters (1991), the size of the atomized droplets varies directly with the viscosity of the solution in an atomization process at constant speed. The higher the viscosity of the solution, the higher 
Table 2. Mean diameter and apparent density of particles produced by conventional spray dryer and VSD.

\begin{tabular}{lcc}
\hline \multicolumn{1}{c}{ Equipment } & Particles mean diameter $(\mu \mathrm{m})$ & Apparent density $\left(\mathrm{g} / \mathrm{cm}^{3}\right)$ \\
\hline Conventional spray dryer & $23.56^{\mathrm{b}} \pm 0.79$ & $0.8519^{\mathrm{a}} \pm 0.0259$ \\
Vacuum spray dryer & $555.83^{\mathrm{a}} \pm 22.26$ & $0.4828^{\mathrm{b}} \pm 0.0081$ \\
\hline
\end{tabular}

Different letters indicate statistically significant differences between the samples produced in the different types of equipment ( $\mathrm{p} \leq 0.05$ ).

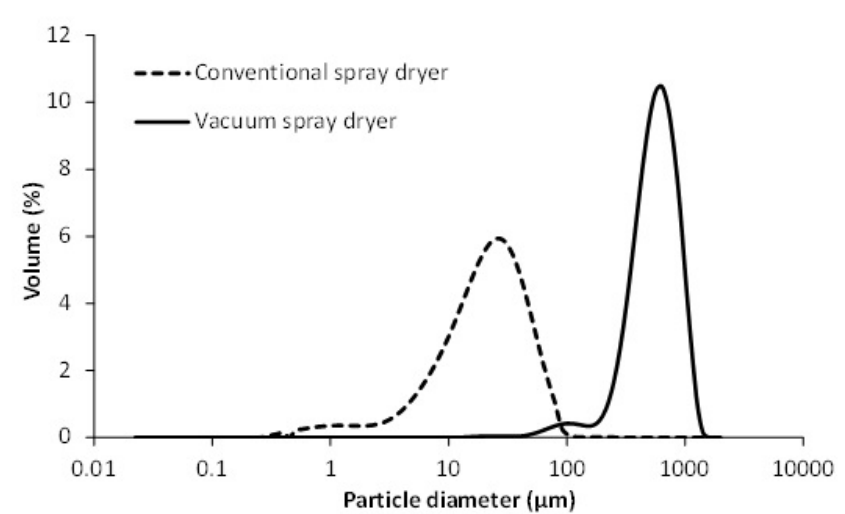

Figure 3. Particle size distributions for the particles produced in VSD and conventional spray dryer.

Table 3. Yield of drying process of conventional spray dryer and VSD.

\begin{tabular}{lc}
\hline \multicolumn{1}{c}{ Equipment } & Process Yield (\%) \\
\hline Conventional spray dryer & $63.98^{\mathrm{a}} \pm 2.33$ \\
Vacuum spray dryer & $23.71^{\mathrm{b}} \pm 1.51$ \\
\hline
\end{tabular}

are the droplets formed during atomization and, consequently, the greater are the obtained particles.

In Figure 3 are shown the particle size distributions for the particles produced in VSD and conventional spray dryer.

\subsection{Yield of drying process}

The yield results of drying process of the particles produced in the two equipment are presented in Table 3.

The samples produced by different devices showed significant differences between them with respect to the efficiency of the drying process. The yield of the spray drying process showed a higher value than the process carried out in VSD, due to the large material retaining in the inner wall of the VSD. The use of high temperatures in conventional equipment resulted in a greater yield of the process, which can be attributed to the improved efficiency of heat and mass transfer processes when the temperature of the drying air is elevated. This is in line with the results published by Tonon et al. (2008), working with spray drying of acai juice.

In VSD, the process yield was adversely affected by the material adhesion on the inner wall of the chamber due to the deposition of feedstock material partially evaporated. To increase the process yield in this drying configuration, it would be necessary a heat supply to the internal wall of the chamber, for example by hot water circulation in a jacket or an increase in the suction flow of the water vapour by the implementation of more vacuum pumps to the system.

\section{Conclusions}

With the vacuum spray dryer developed in this study it was possible to obtain powder product without the use of high temperatures, as in the conventional configuration of the equipment. Thus, the VSD is a viable alternative for drying heat-sensitive compounds. When compared, the products obtained in the spray dryer and VSD showed significant differences. The VSD resulted in larger particles, more soluble and less dense than those obtained in conventional equipment, which led to particles with lower moisture content and consequently lower water activity. The process yield was lower in the VSD to the spray dryer due to partially evaporated material accumulation on the inner walls of the chamber. The heat supply to the internal wall of the chamber or increasing the suction flow of the water vapor could improve the process yield in the VSD.

\section{References}

Al-Kahtani, H. A., \& Hassan, B. H. (1990). Spray drying of roselle (Hibiscus sabdariffa L.) extract. Journal of Food Science, 55(4), 1073-1076. http://dx.doi.org/10.1111/j.1365-2621.1990.tb01601.x.

Aoyama, R., Kitamura, Y., \& Yamazaki, K. (2009). Experimental analysis of spraying and drying characteristics in vacuum spray dryer. Japan Journal of Food Engineering, 10(2), 127-133. http:// dx.doi.org/10.11301/jsfe.10.127.

Association of Official Analytical Chemists - AOAC. (2005). Official methods of Analysis Association of Official Analytical Chemists (16th ed.). Washington, D.C.: AOAC.

Cano-Chauca, M., Stringheta, P. C., Ramos, A. M., \& Cal-Vidal, J. (2005). Effect of the carriers on the microstructure of mango powder obtained by spray drying and its functional characterization. Innovative Food Science \& Emerging Technologies, 6(4), 420-428. http://dx.doi.org/10.1016/j.ifset.2005.05.003.

Carneiro, H. C. F., Tonon, R. V., Grosso, C. R. F., \& Hubinger, M. D. (2013). Encapsulation efficiency and oxidative stability of flaxseed oil microencapsulated by spray drying using different combinations of wall materials. Journal of Food Engineering, 115(4), 443-451. http:// dx.doi.org/10.1016/j.jfoodeng.2012.03.033.

Fu, W.-Y., \& Etzel, M. R. (1995). Spray drying of Lactococcus lactis ssp. lactis C2 and cellular injury. Journal of Food Science, 60(1), 195-200. http://dx.doi.org/10.1111/j.1365-2621.1995.tb05636.x.

Goula, A. M., \& Adamopoulos, K. G. (2004). Spray drying of tomato pulp: effect of feed concentration. Drying Technology, 22(10), 23092330. http://dx.doi.org/10.1081/DRT-200040007.

Goula, A. M., Adamopoulos, K. G., \& Kazakis, N. A. (2004). Influence of spray drying conditions on tomato powder properties. Drying Technology, 22(5), 1129-1151. http://dx.doi.org/10.1081/DRT120038584 .

Islam, M. Z., Kitamura, Y., Yamano, Y., \& Kitamura, M. (2016). Effect of vacuum spray drying on the physicochemical properties, water 
sorption and glass transition phenomenon of orange juice powder. Journal of Food Engineering, 169, 131-140. http://dx.doi.org/10.1016/j. jfoodeng.2015.08.024.

Kenyon, M. M., \& Anderson, R. J. (1988). Maltodextrins and low-dextroseequivalence corn syrup solids. In S. J. Risch \& G. A. Reineccius (Eds.), Flavor encapsulation (chap. 2, ACS Symposium Series, Vol. 370, pp. 7-11). Washington, D.C.: American Chemical Society.

Kitamura, Y., Itoh, H., Echizen, H., \& Satake, T. (2009). Experimental vacuum spray drying of probiotic foods included with lactic acid bacteria. Journal of Food Processing and Preservation, 33(6), 714-726. http://dx.doi.org/10.1111/j.1745-4549.2008.00299.x.

Levine, H., \& Slade, L. (1995). Glass transitions and water-food structure interactions. Advances in Food and Nutrition Research, 38, 103-269. http://dx.doi.org/10.1016/S1043-4526(08)60084-4.

Masters, K. (1991). Spray drying handbook (5th ed.). London: Longman Scientific and Technical.

Reineccius, G. A. (2001). Multiple-core encapsulation: the spray drying of food ingredients. In P. Vilstrup (Ed.), Microencapsulation of food ingredients (pp. 151-185). Surrey: Leatherhead Publishing.
Semyonov, D., Ramon, O., \& Shimoni, E. (2011). Using ultrasonic vacuum spray dryer to produce highly viable dry probiotics. $L W T$ Food Science and Technology (Campinas.), 44(9), 1844-1852. http:// dx.doi.org/10.1016/j.lwt.2011.03.021.

Tonon, R. V., Brabet, C., \& Hubinger, M. D. (2008). Influence of process conditions on the physicochemical properties of açai (Euterpe oleraceae Mart.) powder produced by spray drying. Journal of Food Engineering, 88(3), 411-418. http://dx.doi.org/10.1016/j. jfoodeng.2008.02.029.

Tonon, R. V., Brabet, C., \& Hubinger, M. D. (2009). Influência da temperatura do ar de secagem e da concentração de agente carreador sobre as propriedades físico-químicas do suco de açaí em pó. Ciência e Tecnologia de Alimentos, 29(2), 444-450. http://dx.doi.org/10.1590/ S0101-20612009000200034.

Zare, D., Salehi, A., \& Niakousari, M. (2012). Determination of physical properties of sour orange juice powder produced by a spray dryer. In American Society of Agricultural and Biological Engineers Annual International Meeting (pp. 4240-4253), Dallas, USA. 